\title{
Views of parents on routine measurements of children's growth in schools
}

\author{
L. C. A. Craig, J. Clark and G. McNeill \\ Public Health Nutrition Research Group, University of Aberdeen, Aberdeen AB25 2ZD, UK
}

Research suggests that the majority of parents are unaware of their children's weight status ${ }^{(1,2)}$. Research on parental attitudes to the National Child Measurement Programme $(\mathrm{NCMP})^{(3)}$ in England suggested that most parents would like feedback on their child's results $^{(4)}$. Additional research suggests that providing feedback to parents may have a positive effect on family behaviour and eating habits at home ${ }^{(5)}$.

In England, as part of the NCMP, every year children in reception (4-5 years old) and year 6 (10-11 years old) are weighed and measured and parents receive their child's results, regardless of their weight status, unless they request otherwise. In Scotland, all NHS Boards provide a Child Health Surveillance Programme ${ }^{(4)}$, where all children are routinely offered a health check on entry to primary school including height and weight measurements. These data are used to produce national obesity statistics. However, unlike England these measurements are not routinely fed back to parents.

The aim of the present study was to elicit the views of parents in Grampian, Scotland on providing results of children's height and weight measurements in primary school. Twenty-one schools in Grampian distributed study information to parents of Primary 2 children. Consent was implied by the completion and return of a short questionnaire. Parents were also invited to participate in focus groups to explore opinions in greater depth and seek views on a range of feedback information formats.

Six hundred and thirty questionnaires were distributed and $153(24 \%)$ returned. Sixty five percent of parents felt that all children should have their growth measured in school; $23 \%$ felt it should only be done if parents agree and $7 \%$ only if a health professional thought that there was a problem. Only $3 \%$ felt children's growth should not be measured in school. Eighty eight percent of parents felt that growth measurements in schools should be carried out only by a health professional.

Seventy-three percent felt it would be useful for written results to be given to all parents; $23 \%$ felt that written results should only be provided if the child was overweight or underweight and $3 \%$ felt it would not be useful for parents to receive written information. Fiftyfour percent felt that the information provided should include a chart for parents to monitor growth in the future; over $70 \%$ felt there should be a statement on whether the child's height or weight were in the normal range and over $80 \%$ felt that advice on what to do if the child's height or weight were not within the normal range and the opportunity to discuss results with a health professional should be available.

Initial results from focus groups suggested that parents thought that receiving feedback would be useful but there were some concerns over the sensitivity of the topic and they would like a named contact for further information. There were mixed opinions on mentioning health risks in feedback information and also on whether or not to include a simplified colour-coded BMI chart. However, parents felt it would be useful to include tips for changing behaviour and discussing the subject with the child.

The majority of parents in this sample thought that children's growth should be measured in school by a health professional with written information and further advice fed back to parents, along with the opportunity to discuss the results with a health professional. Further focus groups are in progress to obtain a more representative cross-section of parents' views.

1. Carnell S, Edwards C, Croker H et al. (2005) Parental perceptions of overweight in 3-5 y olds. Int J Obes 29, 353-355.

2. Jeffery AN, Voss LD, Metcalf BS et al. (2005) Parents' awareness of overweight in themselves and their children: cross sectional study within a cohort (EarlyBird 21). BMJ 330, 23-24.

3. Department of Health (2010) The National Child Measurement Programme. www.dh.gov.uk/en/Publichealth/Healthimprovement/Healthyliving/ DH_073787

4. Department of Health (2007) Research into parental attitudes towards the routine measurement of children's height and weight. www.dh.gov.uk/en/ Publicationsandstatistics/Publications/PublicationsPolicyAndGuidance/DH_080600

5. Grimmett C, Croker H, Carnell S et al. (2008) Telling parents their child's weight status: psychological impact of a weight-screening program. Pediatrics 122, e682-e688.

6. ISD Scotland (2009) Child Health Surveillance. http://www.isdscotland.org/isd/2530.html 